\title{
Nutrieconomic model can facilitate healthy and low-cost food choices
}

\author{
Laura Primavesi, Giovanna Caccavelli, Alessandra Ciliberto and Emmanuel Pauze \\ Center Study SPRIM, Nutrition Department, Via Brisa 3, 20133 Milan, Italy
}

Submitted 26 September 2013: Final revision received 4 September 2014: Accepted 15 October 2014: First published online 1 December 2014

\begin{abstract}
Objective: Promotion of healthy eating can no longer be postponed as a priority, given the alarming growth rate of chronic degenerative diseases in Western countries. We elaborated a nutrieconomic model to assess and identify the most nutritious and affordable food choices.

Design: Seventy-one food items representing the main food categories were included and their nationally representative prices monitored. Food composition was determined using CRA-NUT (Centro di Ricerca per gli Alimenti e la Nutrizione) and IEO (Istituto Europeo di Oncologia) databases. To define food nutritional quality, the mean adequacy ratio and mean excess ratio were combined. Both prices and nutritional quality were normalised for the edible food content and for the recommended serving sizes for the Italian adult population.

Setting: Stores located in different provinces throughout Italy.

Subjects: Not applicable.

Results: Cereals and legumes presented very similar nutritional qualities and prices per serving. Seasonal fruits and vegetables presented differentiated nutritional qualities and almost equal prices. Products of animal origin showed similar nutritional qualities and varied prices: the best nutrieconomic choices were milk, oily fish and poultry for the dairy products, fish and meat groups, respectively. Conclusions: Analysing two balanced weekly menus, our nutrieconomic model was able to note a significant decrease in cost of approximately $30 \%$ by varying animal-protein sources without affecting nutritional quality. Healthy eating does not necessarily imply spending large amounts of money but rather being able to make nutritionally optimal choices. The nutrieconomic model is an innovative and practical way to help consumers make correct food choices and nutritionists increase the compliance of their patients.
\end{abstract}

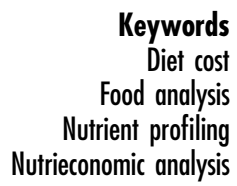

Diet cost
Dits

Food analysis Nutrieconomic analysis
Adoption and promotion of a healthy diet is a priority for reducing chronic diseases including obesity, diabetes, CVD and several cancers. For example, the broad scientific literature demonstrates that greater adherence to a healthy diet, like the Mediterranean diet, is associated with a significant reduction in overall mortality (9\%), mortality from CVD (9\%), incidence of or mortality from cancer (6\%) and incidence of Parkinson's and Alzheimer's disease $(13 \%)^{(1)}$. These data are of major interest. To cite an instance, in the last two decades obesity has more than tripled in Europe, causing more than 1 million deaths and 12 million life-years of illness each year. Moreover, obesity is associated with increased medical costs, premature death, less healthy lifestyle choices, psychological problems and poor quality of life ${ }^{(2)}$. Many governments have taken this problem to heart and developed strategies (i.e. websites improving consumer nutrition knowledge) that can promote food choices that are not only healthy but also economical. Perhaps the most well-known example of these efforts is represented by the US Department of Agriculture's nutrition strategy Choose MyPlate.

Many different factors affect consumer food choices including nutrition knowledge, sensory preferences, food cost and availability, and cultural background ${ }^{(3-5)}$. Social environment and emerging lifestyle conditions, including fragmentation/disruption of family roles and a new pace of work, also induce significant changes in dietary habits ${ }^{(6)}$. Moreover, media suggestions (advertising, fascination with lifestyles other than one's own) influence individuals' food choices and point them towards globalised dietary models ${ }^{(7,8)}$. Taken together, these variables may pose barriers to adopting a healthy diet. Food sensory characteristics and cost seem to have a crucial impact on consumer choices. This latter factor is particularly relevant, 
given that the highest rates of obesity and diabetes are observed among lower-income groups ${ }^{(9-14)}$. Thus, it is possible to speak of a clear social gradient in health: when compared with people of high socio-economic status, people of low socio-economic status show an increased prevalence of morbidity, a high level of health complaints and a lower life expectancy by 7 years ${ }^{(2)}$.

Common wisdom suggests that healthier foods are more expensive than less healthy choices ${ }^{(12,15)}$. Food cost comparisons may be performed using three price metrics: the price per energy $(\mathrm{kJ} / \mathrm{kcal})$, per edible gram and per average serving. The method by which food prices are compared has a great effect on findings related to food cost comparisons. Foods low in energy for a given weight, typically fruit and vegetables, appear to have a higher price when expressed per kilojoule. Conversely, less healthy foods (sugar- and fat-rich foods) tend to be high in energy and to have a low price per kilojoule. Finally, when measured based on edible weight or average serving size, grains, vegetables, fruit and dairy foods are less expensive than most protein foods and foods high in saturated fat and added sugars ${ }^{(16,17)}$.

The main purpose of the present study was to select the most affordable healthy foods and to demonstrate that it is possible to follow a healthy diet without heavy economic effort. To reach these objectives, we calculated the nutrient adequacy of different foods, using the mean adequacy ratio (MAR) and the mean excess ratio (MER) ${ }^{(18)}$, and subsequently correlated each food's MAR and MER with its cost. This allowed us to link nutrient density and food prices and to compare the costs of foods from a given food category according to their nutritional quality (NQ). Our nutrieconomic model (NEM) notes the most economical choices among similar foods and represents an important tool to help consumers identify foods that provide optimal nutrition at lowest possible cost.

\section{Materials and methods}

\section{Food items}

The main food categories in the Italian Food Pyramid (Istituto di Scienza dell'Alimentazione, Università la Sapienza, Roma) ${ }^{(19)}$ were included in the present study: non-starchy vegetables, fruit, dairy products, cereals and starchy vegetables, legumes, fish, poultry and red meat. A total of seventy-one food items belonging to these groups were chosen on the basis of their cost and availability; particularly for fruit and vegetables, seasonal choices were preferred.

\section{Food price survey}

Each food cost was represented by the mean price over a 4-week monitoring period (April 2013); price data were collected using the SMS CONSUMATORI website ${ }^{(20)}$, an innovative free service offered by the Italian Ministry of
Agricultural, Food and Forestry Policies. This tool considered the most popular food items and collected their daily retail prices in 2200 different stores (hyper- and supermarkets, discount stores, fruit and vegetable stores, butchers, fishmongers, grocery stores and street markets) located in thirty-five different provinces throughout Italy.

The prices determined in this way were then referred to the recommended servings for the Italian adult population reported in Table $1^{(19)}$. Moreover, each price was normalised according to the edible part of each considered food (data sources: CRA-NUT, Centro di Ricerca per gli Alimenti e la Nutrizione and IEO, Istituto Europeo di Oncologia) ${ }^{(21,22)}$.

\section{Nutritional evaluation}

To assess the nutritional quality (NQ) of each food item, the MAR was calculated as follows ${ }^{(18)}$ :

$$
\text { MAR }=\frac{1}{n} \times \sum_{b n=1}^{n} \frac{\operatorname{INTAKE}_{b n}}{\operatorname{RDA}_{b n}} \times 100,
$$

where $n$ is the number of beneficial nutrients considered, $b n$ is an index identifying one of the beneficial nutrients, INTAKE $_{b n}$ is the amount of beneficial nutrient $b n$ provided by a recommended serving of food and $\mathrm{RDA}_{\mathrm{bn}}$ is the daily amount of beneficial nutrient $b n$ according to its RDA.

Each ratio was truncated at 100 so that a high intake of one nutrient could not compensate for the low intake of another. Energy density and twenty-eight beneficial nutrients were considered: energy intake, total proteins, total and polyunsaturated fats, total fibre, water-soluble (C, thiamin, riboflavin, niacin, pantothenic acid, pyridoxine, biotin, folic acid and cyanocobalamin) and fat-soluble vitamins (A, D and $\mathrm{E})$ and, finally, various mineral elements $(\mathrm{Ca}, \mathrm{Cl}, \mathrm{Cu}$, iodine, Fe, Mg, Mn, P, K, Se and $\mathrm{Zn}$ ). For dietary protein sources, e.g. meat, fish, legumes and dairy products, essential amino acids (histidine, isoleucine, leucine, lysine, methionine + cysteine, phenylalanine + tyrosine,

Table 1 Recommended servings of analysed food items for the Italian adult population ${ }^{(19)}$

\begin{tabular}{lcr}
\hline Food & Weekly consumption & Serving $(\mathrm{g})$ \\
\hline Fruit and vegetables & & \\
Vegetables & 14 & 250 \\
Fresh leafy vegetables & 14 & 50 \\
$\quad$ Fruit & 21 & 150 \\
Cereals & 16 & 50 \\
Bread & 8 & 80 \\
Dried pasta and rice & 7 & 20 \\
Bakery products & 5 & \\
Meat, fish and legumes & 2 & 100 \\
Meat & 2 & 50 \\
Cured meats & 2 & 150 \\
Fish & & 30 \\
Dried legumes & 14 & 125 \\
Milk and dairy products & 4 & 100 \\
Milk and yoghurt & 4 & 50 \\
Fresh cheese & & \\
Seasoned cheese & & \\
\hline
\end{tabular}


threonine, tryptophan and valine) were also considered. Single nutrients were included if a specific daily RDA for the Italian adult population was available from the Italian Society of Human Nutrition (Società Italiana de Nutrizione Umana; SINU) ${ }^{(23)}$. Daily requirements of essential amino acids were calculated on the basis of a mean protein intake of $0.66 \mathrm{~g}$ protein $/ \mathrm{kg}$ body weight per $\mathrm{d}$ for adult males and females ${ }^{(24,25)}$.

Definitions of 'healthy food' vary depending on the source and context, but in a general way healthy foods provide essential nutrients, support health and contain only moderate amounts of saturated fats, free sugars and $\mathrm{Na}^{(26)}$. Thus, as a global nutritional assessment, MAR was reduced by its counterpart mean excess ratio (MER), which was calculated for fats, free sugars and $\mathrm{Na}$, as follows ${ }^{(18)}$ :

$$
\operatorname{MER}=\left[\frac{1}{3} \times\left(\sum_{n l=1}^{3} \frac{\operatorname{INTAKE}_{n l}}{\operatorname{MRV}_{n l}} \times 100\right)\right]-100,
$$

where $n l$ is an index identifying one of the nutrients to limit, $\mathrm{INTAKE}_{n l}$ is the amount of nutrient $n l$ provided by a recommended serving of food and $\mathrm{MRV}_{n l}$ is the daily maximum recommended value for nutrient $n l$.

In particular, SINU recommends limiting daily $\mathrm{Na}$ intake to a maximum of $2 \mathrm{~g}$ and intake of free sugars and saturated fats to less than $15 \%$ and $10 \%$ of total energy intake, respectively. To calculate MER, each ratio below 100 was set to 100 , so that a low intake of one nutrient could not compensate for the high intake of another. To note that all selected foods presented a null MER. In principle, maximum NQ quality scored 100 (maximum MAR and null MER).

The chemical composition of each food was determined using the CRA-NUT and IEO databases and normalised for the recommended serving.

\section{Nutrieconomic charts}

A nutrieconomic chart was defined for each food group, reporting the NQ and price of each analysed food item along the $x$ - and $y$-axis, respectively. This graphical solution allowed immediate comparisons between similar foods and identification of the best nutrieconomic choices in each food category. Nutrieconomic charts comparing different food categories were not performed, except for the typical protein sources (meat, fish, legumes and dairy products), as each food group provides unique nutritional benefits and offers different macronutrients (carbohydrates, proteins and fats) and micronutrients (vitamins and minerals).

\section{Results}

\section{The importance of the recommended serving}

As previously discussed, a nutritional comparison among different foods could be based on price per kilojoule, per $100 \mathrm{~g}$ or per average serving size. Even if the first two methods seem to be more universally comprehensible than recommended servings, which very often differ according to country, these approaches do not consider that different foods are consumed in very different amounts. These methods dramatically affect the results of food comparisons aimed to identify nutritionally optimal choices.

\section{Nutrieconomic model for food groups: identifying the best nutrieconomic choices}

Considering cereals and their derivatives, our NEM revealed a homogeneous NQ for this group (data not shown). These products presented similar NQ as well as similar cost, except for bread and rusks, taking into consideration their smaller serving sizes $(50 \mathrm{~g}$ and $20 \mathrm{~g}$, respectively, $v .80 \mathrm{~g}$ of pasta/rice). Unfortunately, the official price database did not include data about whole grains, which most likely represent the best nutrieconomic choices in this category. This lack reflected the still insufficient consumption of these products by Italian consumers.

In the fruit and vegetables group, NQ varied substantially, while cost showed a narrow range because the foods selected represented seasonal choices (Fig. 1). In this scenario, spinach emerged for its excellent NQ, due to a high content of riboflavin, vitamins $\mathrm{C}$ and $\mathrm{A}$, folic acid, pyridoxine, Fe and $\mathrm{Zn}$. Artichokes showed a very good NQ but also had the highest cost per serving.

In the meat (Fig. 2) and fish (Fig. 3) groups, the NEM showed a wide range of food cost for a relatively similar NQ per serving. Within the meat group, poultry such as chicken and turkey without skin represented the best nutrieconomic choice. In the fresh fish group, the best balance between NQ and cost per serving was reached by oily fish such as anchovy and mackerel. It is interesting to note the case of sole, which in Italy is often recommended for children: it has a very similar NQ to others but a much higher price per serving.

In the milk and dairy products group, all food items showed a very similar NQ, with a quite wide range of cost per serving (Fig. 4). The best nutrieconomic choice was represented by milk (pasteurised or ultra-heat-treated), followed by yoghurt.

Dried legumes (beans, chickpeas and lentils) showed almost the same cost (approximately $0 \cdot 1 €$ ) and NQ (approximately 25) per serving (30 g).

\section{Nutrieconomic model among dietary protein sources}

Each food category offers specific nutrients and, therefore, a balanced and varied diet must include the correct intake of all types of food items. Figure 5 presents the NEM results among typical dietary protein sources, namely meat, fish, legumes and dairy products. When this comparison referred to $100 \mathrm{~g}$, almost all dietary protein sources 


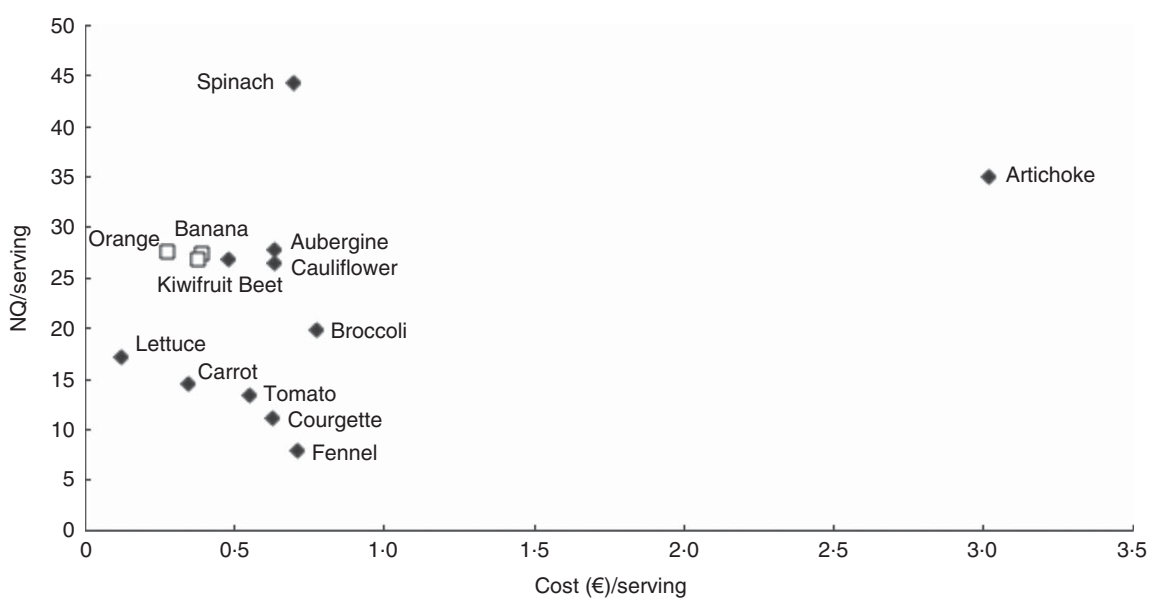

Fig. 1 Fruit and vegetables nutrieconomic chart: nutritional quality (NQ) and cost referred to the recommended serving, namely $150 \mathrm{~g}$ for fruit $(\square), 250 \mathrm{~g}$ for cooked vegetables $(\diamond)$ and $50 \mathrm{~g}$ for fresh leafy vegetables $(\diamond)$

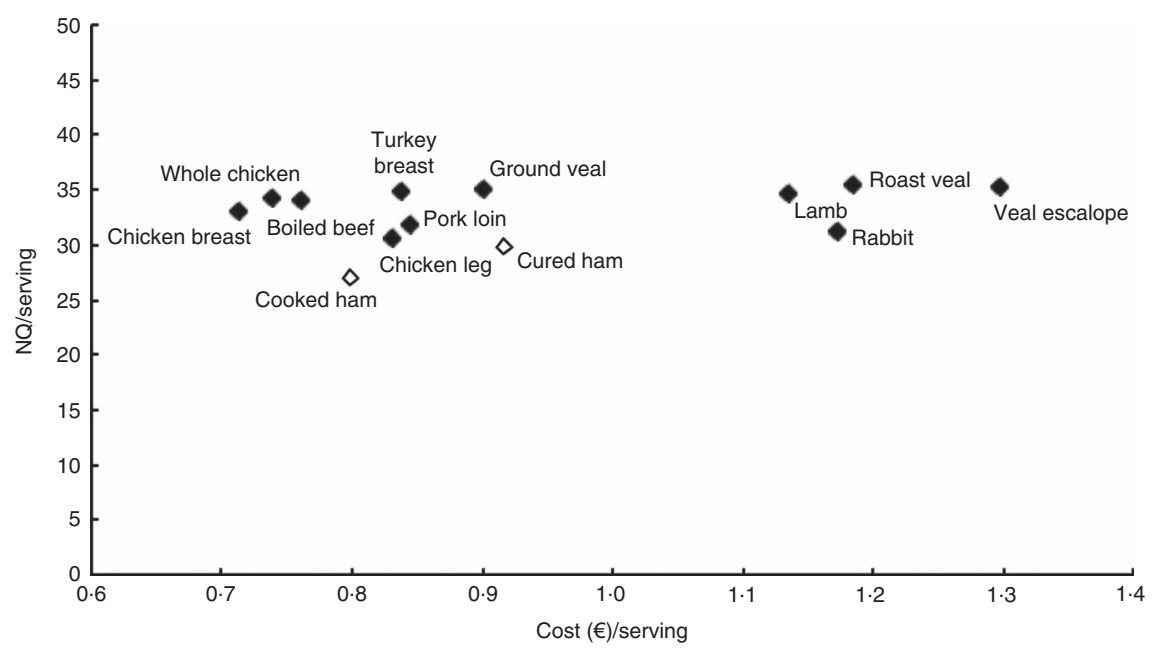

Fig. 2 Meat nutrieconomic chart: nutritional quality (NQ) and cost referred to the recommended serving, namely $100 \mathrm{~g}$ for fresh meat $(\diamond)$ and $50 \mathrm{~g}$ for deli meats $(\diamond)$

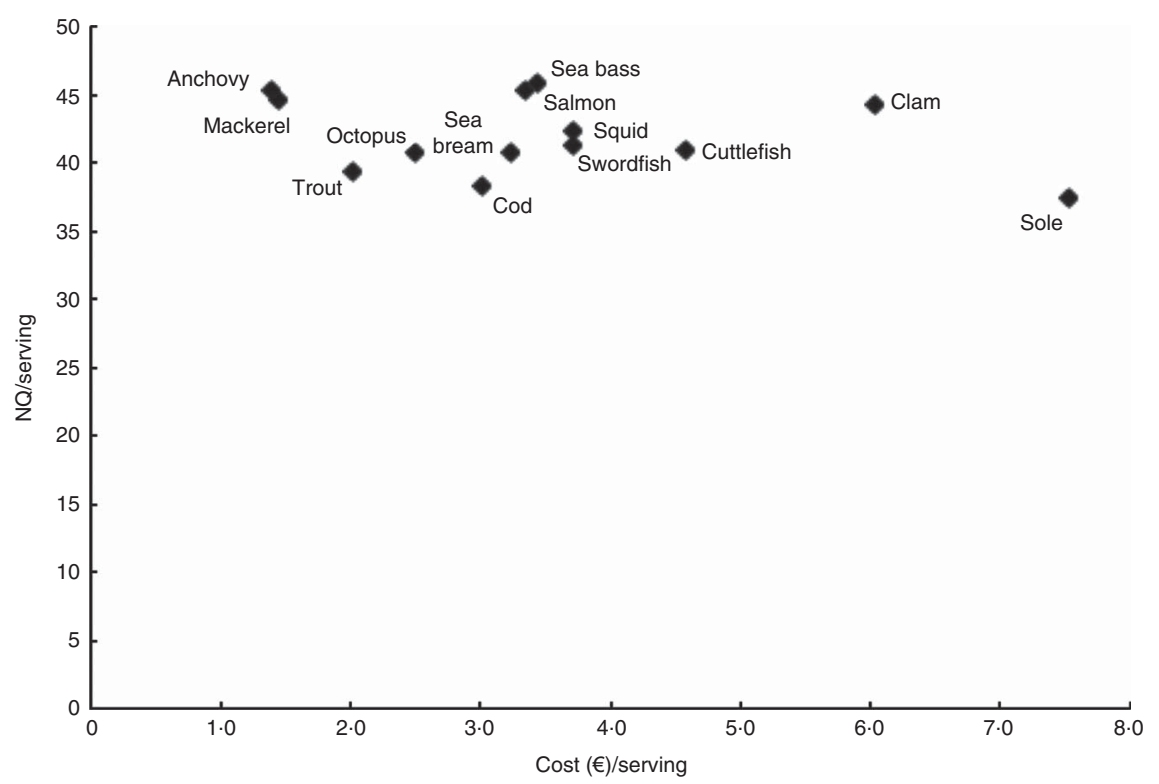

Fig. 3 Fresh fish nutrieconomic chart: nutritional quality (NQ) and cost referred to the recommended serving (150 g) 


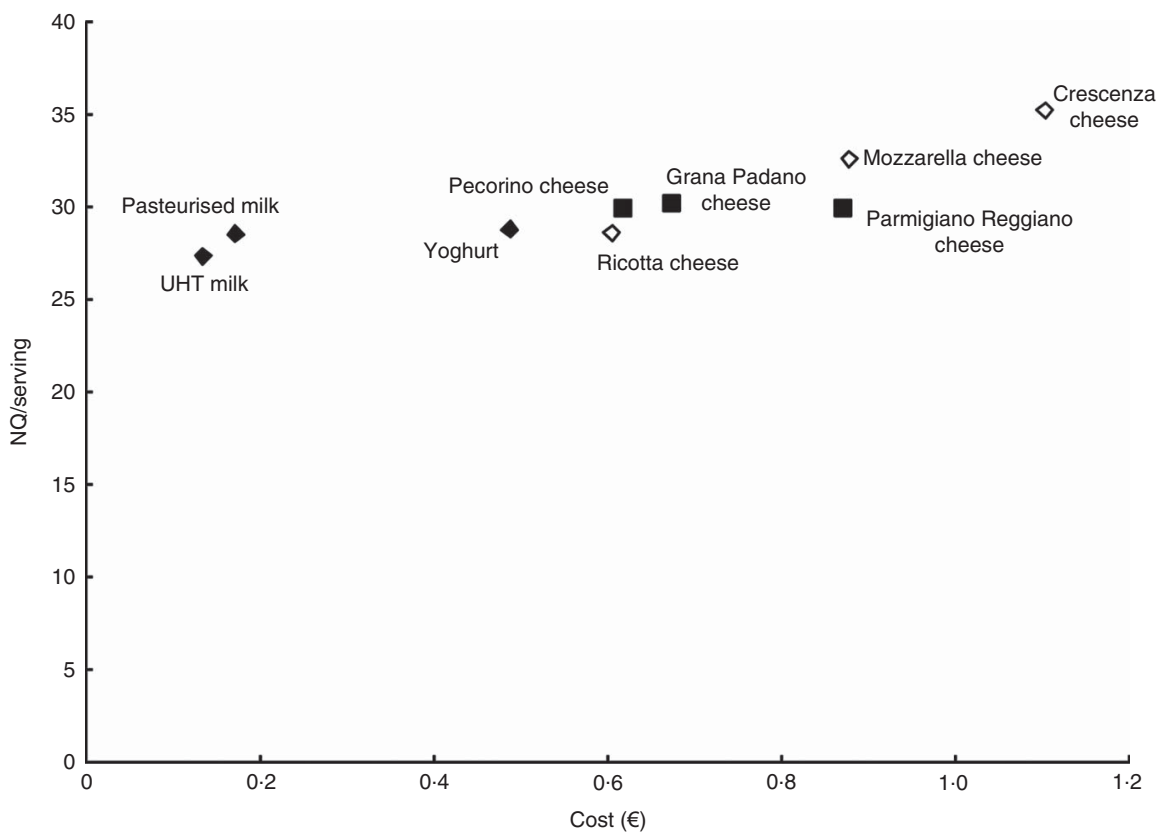

Fig. 4 Milk and dairy products nutrieconomic chart: nutritional quality (NQ) and cost referred to the recommended serving, namely $125 \mathrm{ml}$ for milk and yoghurt $(\diamond), 50 \mathrm{~g}$ for aged cheeses $(\diamond)$ and $100 \mathrm{~g}$ for fresh cheeses $(\diamond)$. UHT, ultra-heat-treated

showed a quite similar NQ (Fig. 5(a)). On the contrary, when the recommended serving was considered, NQ differed among each food category (Fig. 5(b)). In particular, this second approach noted the higher NQ of products of animal origin, i.e. fresh meat, fish and dairy products, in comparison to vegetal protein sources, i.e. legumes. The higher NQ for meat and fish could be explained by considering that the recommended serving for meat and fish is approximately 100 and $150 \mathrm{~g}$, while the recommended serving for dried legumes corresponds to approximately $30 \mathrm{~g}$. Considering the single nutrient profiles per serving, animal-origin foods presented a higher total protein content, better satisfying the recommended daily protein intake. Their supply of essential amino acids fulfilled the specific recommended intake, while that of legumes was slightly lower.

\section{Simulation of a weekly menu: is a low-cost balanced diet possible?}

Based on the results presented above, it is clear that, in some categories, food items showed a very similar NQ while their price per serving varied. This was the case for animal-protein sources including meat, fish and dairy products. In a balanced diet based on the recommended serving of the Italian Food Pyramid (Table 1), meat can be eaten up to five times per week, equally distributed among beef, pork and poultry; fish should be consumed at least two times per week; and recommended consumption of cheese is approximately four times weekly ${ }^{(19)}$.

We therefore formulated two balanced weekly menus, differing only in their content of meat, fish and dairy products, as shown in Table 2. The first menu included the most economical choices, while in the second the more expensive choices were preferred. Just varying these few servings, the high-cost diet accounted for $48 €$ per person, while the lowcost diet reached only $35 €$ per person: a saving of almost $30 \%$, without affecting the nutritional quality of the diet.

\section{Discussion}

The cost of healthy eating has become a growing concern in industrialised countries. Several studies have already demonstrated that the adherence to dietary guidelines for the prevention of cancer, obesity or CVD can be influenced by social, educational and material resources and in particular by food prices and diet costs ${ }^{(10-13)}$. Developing nutrient profile models to help consumers identify affordable nutrient-rich foods across and within food groups has implications for nutrition education, food policy and public health ${ }^{(27-30)}$.

Food comparisons differ according to the method used to calculate $\operatorname{cost}^{(31)}$. While food prices per gram do not reflect differences in the foods' moisture content and therefore energy density, food prices per kilojoule do not note nutritious differences, such as the content of vitamins and minerals. For example, measuring food prices per gram, rather than per kilojoule, is one way to make healthy foods, like fruit and vegetables, appear less expensive. Therefore, it is of primary importance to find measures assessing the amounts of beneficial nutrients per unit cost, such as the already proposed Nutrient Rich Food Index ${ }^{(32,33)}$. Ideally, the proposed system would be science-based and user-friendly, allowing consumers to make more healthful food choices within and across all food groups. 
(a)

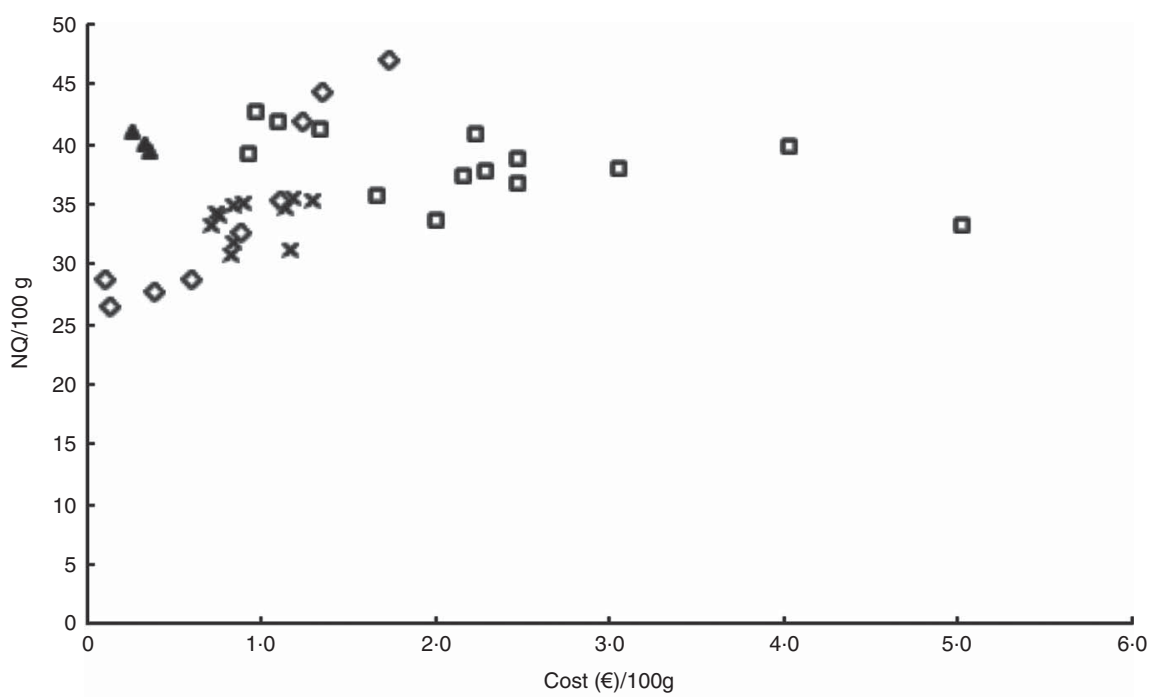

(b)

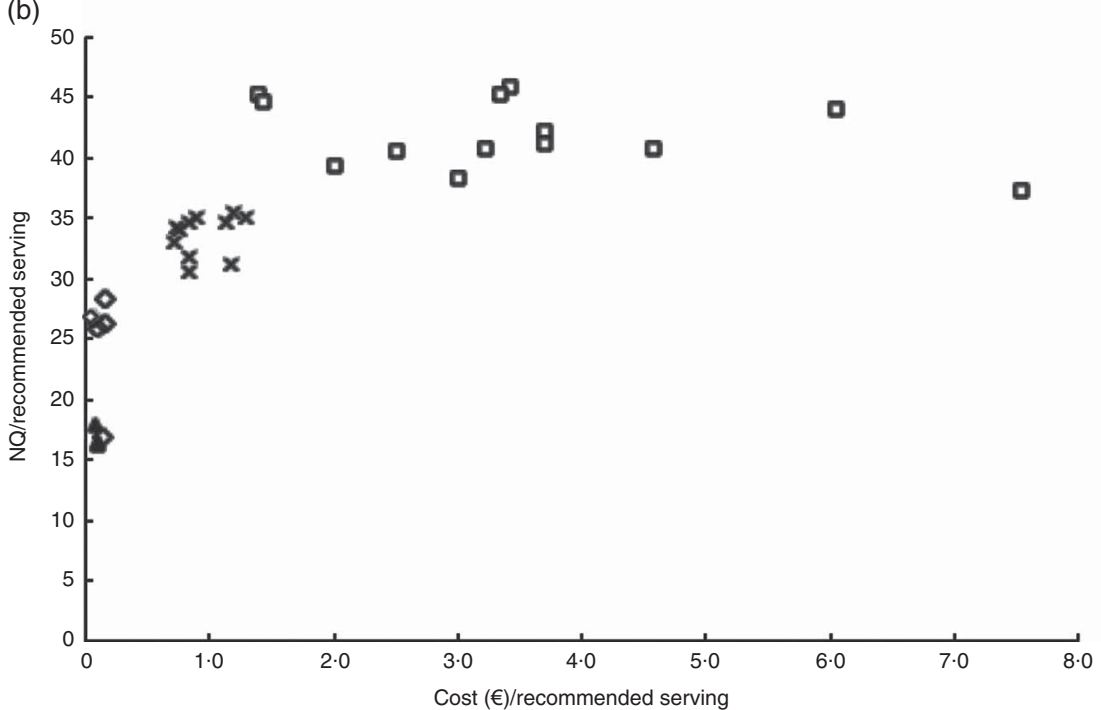

Fig. 5 Application of the nutrieconomic model among dietary protein sources ( $\times$, meat; $\square$, fish; $\boldsymbol{\Delta}$, dried legumes; $\diamond$, dairy products): (a) nutritional quality (NQ) and cost referred to $100 \mathrm{~g}$; (b) NQ and cost referred to recommended serving, i.e. $100 \mathrm{~g}$ for meat, $150 \mathrm{~g}$ for fish, $30 \mathrm{~g}$ for dried legumes, $125 \mathrm{ml}$ for milk and yoghurt, and 100 and $50 \mathrm{~g}$ for fresh and aged cheeses, respectively

The present study aimed to define the most affordable and nutritional foods in each food group, basing its results on MAR and MER indices and considering several beneficial nutrients. Selected foods belonged to the main groups of the Italian Food Pyramid: in fact, the secondary purpose of the present study was to demonstrate that a healthy balanced diet is not as expensive as consumers generally think and that it is truly sustainable from an economic point of view.

We decided to perform nutrition profiling of foods based on their recommended serving rather than on the $100 \mathrm{~g}$ reference. In the European Union, nutrition labelling is provided per $100 \mathrm{~g}$, while in the USA such information is referred to serving size, as defined by the Food and
Drug Administration. Each method has its own advantages and disadvantages. Evaluating the nutrient content of foods in relation to energy (per $100 \mathrm{~kJ} / 100 \mathrm{kcal}$ ) allows for ready comparisons with nutrient recommendations and guidelines, typically expressed per approximately $8372 \mathrm{~kJ}$ (2000 kcal) daily. However, some foods score disproportionately high by virtue of their low energy density, typically fruit and vegetables ${ }^{(30)}$. Moreover, typical serving sizes for different foods can deviate significantly from the standard of $100 \mathrm{~g}$. For example, serving sizes for legumes, baked products or cured cheeses are typically much smaller than $100 \mathrm{~g}$. In contrast, serving sizes for milk or yoghurt, fish, vegetables or fruit are well in excess of $100 \mathrm{~g}$. Thus, expressing nutrient content on a 
Table 2 Weekly diet simulation of two different menus, differing by food protein sources. Menu 1 includes the best nutrieconomic food choices and menu 2 the more expensive food choices. Equal foods in the two menus are marked with an X

\begin{tabular}{|c|c|c|}
\hline \multicolumn{3}{|c|}{ WEEKLY DIET SIMULATION } \\
\hline Food group (suggested times/week) & $\begin{array}{l}\text { Menu } 1 \text { (including best nutrieconomic } \\
\text { food choices) }\end{array}$ & $\begin{array}{l}\text { Menu } 2 \text { (including more expensive } \\
\text { food choices) }\end{array}$ \\
\hline \multicolumn{3}{|l|}{ Vegetables (14) } \\
\hline Green leafy vegetables (6) & $\mathrm{X}$ & $\mathrm{X}$ \\
\hline Cauliflower (1) & $\mathrm{X}$ & $\mathrm{X}$ \\
\hline Broccoli (1) & $\mathrm{X}$ & $\mathrm{X}$ \\
\hline Spinach (2) & $\mathrm{X}$ & $x$ \\
\hline Carrot (1) & $\mathrm{X}$ & $\mathrm{X}$ \\
\hline Aubergine (1) & $\mathrm{X}$ & $\mathrm{X}$ \\
\hline Tomato (2) & $\mathrm{X}$ & $\mathrm{X}$ \\
\hline Fennel (1) & $\mathrm{X}$ & $x$ \\
\hline \multicolumn{3}{|l|}{ Fruits (21) } \\
\hline Orange (7) & $\mathrm{X}$ & $\mathrm{X}$ \\
\hline Banana (7) & $\mathrm{X}$ & $\mathrm{X}$ \\
\hline Kiwifruit (7) & $\mathrm{X}$ & $\mathrm{X}$ \\
\hline \multicolumn{3}{|l|}{ Cereals (33) } \\
\hline Bread (16) & $\mathrm{X}$ & $\mathrm{X}$ \\
\hline Pasta (4) & $\mathrm{X}$ & $\mathrm{X}$ \\
\hline Rice (4) & $\mathrm{X}$ & $x$ \\
\hline Bakery products (7) & $\mathrm{X}$ & $\mathrm{X}$ \\
\hline Potatoes (2) & $X$ & $x$ \\
\hline \multicolumn{3}{|l|}{ Dairy products (18) } \\
\hline Milk (7) & $\mathrm{X}$ & $\mathrm{X}$ \\
\hline Yoghurt (7) & $\mathrm{X}$ & $x$ \\
\hline Cheese (4) & Ricotta cheese (2) & Crescenza cheese (1) \\
\hline & Grana Padano cheese (2) & Mozzarella cheese (1) \\
\hline & & Parmigiano Reggiano cheese (2) \\
\hline \multicolumn{3}{|l|}{ Meat products $(7)$} \\
\hline Cooked ham (1) & $\mathrm{X}$ & $\mathrm{X}$ \\
\hline Cured ham (1) & $\mathrm{X}$ & $x$ \\
\hline Pork loin (2) & $\mathrm{X}$ & $\mathrm{X}$ \\
\hline Meat (3) & Ground veal (1) & Veal escalope (1) \\
\hline & Chicken breast (2) & Rabbit (2) \\
\hline Fish products (2) & Anchovies (2) & Salmon (1) \\
\hline & & Sole (1) \\
\hline \multicolumn{3}{|l|}{ Other protein sources (4) } \\
\hline Egg (2) & $\mathrm{X}$ & $\mathrm{X}$ \\
\hline Legumes (2) & $\mathrm{X}$ & $\mathrm{x}$ \\
\hline \multicolumn{3}{|l|}{ Fat source (20) } \\
\hline Extra virgin olive oil & $\mathrm{X}$ & $\mathrm{X}$ \\
\hline Total weekly nutritional quality & $85 \cdot 7$ & 81.5 \\
\hline Total weekly cost/person & $35 €$ & $48 €$ \\
\hline
\end{tabular}

per serving/portion basis is the only approach directly related to the quantity of food typically consumed.

Each food category shows a different nutritional profile, providing characteristic families of nutrients. In this sense, when a unique nutritional index is used, we considered nutritional comparisons among different categories as quite hazardous, preferring comparisons among food items belonging to the same group. We carried out just one inter-category comparison: among dietary protein sources.

Cereals showed the lowest prices per portion, with similar values for NQ. Therefore, consumers can choose what they prefer.

Considering the fruit and vegetables group, we intentionally analysed seasonal products. The NEM highlighted a very peculiar situation: almost all of the foods we considered showed a similar price per serving, while a wide range of NQ was apparent. Considering the high number of portions recommended during a week, the best nutrieconomic choice is to vary fruit and vegetables as much as possible, always favouring local and seasonal products. In this way, consumers can ensure an optimum intake of all nutrients and save money.

All meats presented quite similar values for NQ together with a wide range of prices per serving. This means that consumers can choose, for the same nutritional profile, more affordable foods. Poultry meat, such as chicken and turkey without skin, is the best nutrieconomic choice for this food category. Oily fish, such as anchovy and mackerel, represent the best nutrieconomic choice among fish. This is not surprising, but it is a further confirmation of the exceptional nature of these staple foods of the traditional Mediterranean diet. For dairy products, milk and yoghurt are the most affordable foods. 
Considering dietary protein sources, animal products presented higher NQ, as well as a higher price per serving, particularly for the fish group.

The above examples give an idea of how, within the same dietary pattern, differences in spending can be wide according to the food choices of each consumer. Simply by varying the portions related to the protein food sources from the most expensive to the cheapest, we showed savings of $30 \%$ per week without affecting the nutritional quality of the diet.

Therefore, we believe that policies that favour better nutrition must necessarily consider price as a fundamental variable and that significant investments should be directed to food education. Eating healthily does not necessarily imply spending much, but rather being able to make nutritionally optimal choices. In this sense, the NEM is an innovative, useful and practical tool to help both consumers in making correct food choices and nutritionists in increasing the compliance of their patients.

The primary aim of NEM was to investigate the best food choices among healthy foods, demonstrating the sustainability of healthy diets. Further development of NEM will compare typical fast foods or ready-to-eat foods with homemade recipes prepared with healthy ingredients, such as those considered in this first analysis.

\section{Acknowledgements}

Financial support: This research received no specific grant from any funding agency in the public, commercial or notfor-profit sectors. Conflict of interest: None. No party with a financial interest of any kind in the study or its outcome was involved in study implementation, data collection, data analysis or interpretation. Authorship: A.C. and E.P. contributed to the design and oversight and critical review of the study; L.P. and G.C. analysed the data and wrote the manuscript. Ethics of human subject participation: Ethical approval was not required.

\section{References}

1. Sofi F, Cesari F, Abbate R et al. (2008) Adherence to Mediterranean diet and health status: meta-analysis. BMJ 337, a1344.

2. Burkert NT, Rásky E, Großschädl F et al. (2013) The influence of socioeconomic factors on health parameters in overweight and obese adults. PLoS One 8, e65407.

3. Raynor HA, Kilanowski CK, Esterlis I et al. (2002) A cost-analysis of adopting a healthful diet in a familybased obesity treatment program. J Am Diet Assoc 102, 645-650.

4. Rolls BJ (2000) The role of energy density in the overconsumption of fat. J Nutr 130, 2S Suppl., 268S-271S.

5. Blundell JE \& MacDiarmid JI (1997) Fat as a risk factor for overconsumption: satiation, satiety, and patterns of eating. J Am Diet Assoc 97, S63-S69.
6. Saulle R, Semyonov L \& La Torre G (2013) Cost and costeffectiveness of the Mediterranean diet: results of a systematic review. Nutr 5, 4566-4586.

7. Schmidhuber J \& Traill WB (2006) The changing structure of diets in the European Union in relation to healthy eating guidelines. Public Health Nutr 9, 584-595.

8. Bonaccio M, Bonanni AE, Di Castelnuovo A et al. (2012) Low income is associated with poor adherence to a Mediterranean diet and a higher prevalence of obesity: cross-sectional results from the Moli-sani study. BMJ Open $\mathbf{2}$, e001685.

9. Drewnowski A \& Eichelsdoerfer P (2009) The Mediterranean diet: does it have to cost more? Public Health Nutr 12, $1621-1628$.

10. Darmon N \& Drewnoski A (2008) Does social class predict diet quality? Am J Clin Nutr 87, 1107-1117.

11. Neff RA, Palmer AM, McKenzie SE et al. (2009) Food systems and public health disparities.J Hunger Environ Nutr $\mathbf{4}$, 282-314.

12. Drewnowski A \& Darmon N (2005) Food choices and diet costs: an economic analysis. J Nutr 135, 900-904.

13. Hiza HB, Casavale KO, Guenther PM et al. (2013) Diet quality of Americans differs by age, gender, race/ ethnicity, income and education level. J Acad Nutr Diet 113, 297-306.

14. Kirkpatrick SI, Dodd KW, Reedy J et al. (2012) Income and race/ethnicity are associated with adherence to food-based dietary guideline among US adults and children. J Acad Nutr Diet 112, 624-635.

15. Drewnowski A \& Darmon N (2005) The economics of obesity: dietary energy density and energy cost. Am J Clin Nutr 82, 1 Suppl., 265S-273S.

16. Carlson A \& Frazão E (2014) Food costs, diet quality and energy balance in the United States. Physiol Behav 134, 2031.

17. Rao M, Afshin A, Singh G et al. (2013) Do healthier foods and diet patterns cost more than less healthy options? A systematic review and meta-analysis. BMJ Open 3, e004277.

18. Vieux F, Soler LG, Touazi D et al. (2013) High nutritional quality is not associated with low greenhouse gas emissions in self-selected diets of French adults. Am J Clin Nutr $\mathbf{9 7}$, 569-583.

19. Istituto di Scienza dell'Alimentazione, Università La Sapienza (2014) Piramide Alimentare. http://www.piramidealimentare. it/ (accessed November 2014).

20. Ministero delle Politiche Agricole, Alimentari e Forestali (2013) SMS consumatori. www.smsconsumatori.it.

21. Centro di Ricerca per gli Alimenti e la Nutrizione (2014) Tabelle di composizione degli alimenti. http://nut.entecra. it/646/tabelle_di_composizione_degli_alimenti.html (accessed November 2014).

22. Istituto Europeo di Oncologia (2014) Banca dati di composizione degli alimenti per studi epidemiologici in Italia. http://www.bda-ieo.it/ (accessed November 2014).

23. Società Italiana de Nutrizione Umana (2012) LARN Livelli di Assunzione di Riferimento di Nutrienti ed energia per la popolazione italiana. Documento de sintesi per il XXXV National Congresso Nazonale SINU, Bologna, 22-23 ottobre 2012. http://www.sinu. it/documenti/20121016_larn_bologna_sintesi_prefinale.pdf (accessed November 2014).

24. World Health Organization, Food and Agriculture Organization of the United Nations \& United Nations University (2007) Protein and Amino Acid Requirements in Human Nutrition. Report of a Joint FAO/WHO/UNU Expert Consultation. WHO Technical Report Series no. 935. Geneva: WHO.

25. European Food Safety Authority, Panel on Dietetic Products, Nutrition and Allergies (2012) Scientific Opinion on Dietary Reference Values for protein. EFSA J 10, 2557. 
26. Carlson A \& Frazão E (2012) Are Healthy Foods Really More Expensive? It Depends on How You Measure the Price. Economic Information Bulletin no. EIB-96. Washington, DC: Economic Research Service, USDA.

27. Drewnowski A \& Specter SE (2004) Poverty and obesity: the role of energy density and energy costs. Am J Clin Nutr 79, 6-16.

28. Drewnowski A \& Barratt-Fornell A (2004) Do healthier diets cost more? Nutr Today 39, 161-168.

29. Andrieu E, Darmon N \& Drewnowski A (2006) Low cost diets: more energy, fewer nutrients. Eur J Clin Nutr 60 434-436.
30. Drewnowski A (2013) New metrics of affordable nutrition: which vegetables provide most nutrients for least cost? J Acad Nutr Diet 113, 1182-1187.

31. Drewnowski A, Maillot M \& Darmon N (2009) Should nutrient profiles be based on $100 \mathrm{~g}, 100 \mathrm{kcal}$ or serving size? Eur J Clin Nutr 63, 898-904.

32. Drewnowski A (2009) Defining nutrient density: development and validation of the nutrient rich foods index. J Am Coll Nutr 28, issue 4, 421S-426S.

33. Drewnowski A (2010) The Nutrient Rich Foods Index helps to identify healthy, affordable foods. Am J Clin Nutr $\mathbf{9 1}$, issue 4, 1095S-1101S. 